\title{
Management of the Neuropathic Bladder by Clean Intermittent Catheterisation: 5 Year Outcomes
}

\author{
F. M. Maynard, M.D., J. Glass, D.O. \\ University of Michigan, Department of Physical Medicine and Rehabilitation, 1500 \\ E. Medical Centre Drive, Ann Arbor, Michigan 48109-0042, U.S.A.
}

\begin{abstract}
Summary
Based on a telephone interview and medical record review of the urological outcomes among 40 spinal cord injury patients with a neuropathic bladder at discharge who were an average of 60 months post-injury and who were all initially managed by chronic clean intermittent catheterisation $(C C I C)$, the following conclusions were made: Over $80 \%$ of patients using CCIC at discharge continued to use it, suggesting low morbidity and high patient acceptance; Urological complications in patients using CCIC were more frequent in the lower urinary tract than in the upper urinary tract, were more frequent in men than women, and had a low morbidity; Urological complications and hospitalisations were more frequent among the $41^{\circ}{ }_{0}$ of patients using CCIC who had frequent SxUTIs; SxUTIs were common in patients using CCIC but rates may be comparable with other methods; Although $44^{\circ}$ of $C C I C$ patients were hospitalised at least once in 5 years for urological complications, this is comparable to reported multi-centre outcomes in the U.S.A. (Young, 1982).
\end{abstract}

Key words: Spinal cord injury; Urological outcomes; Clean intermittent catheterisation.

\section{Introduction}

Intermittent catheterisation was recently reported to be the most common method of bladder management at discharge from a model spinal cord injury care system in the U.S.A., being used by $30^{\circ} \%$ of patients with new injuries (Stover et al., 1985). As a result of the increasing use of intermittent urethral catheterisation, either with a sterile or a clean technique, it is becoming more important to document the long-term medical consequences of this form of management, its social acceptance over time and its cost-effectiveness. This study reports 5-year urological outcomes in a population of new spinal cord injury patients who were all managed initially by a clean technique of intermittent catheterisation. 


\section{Patients and methods}

Between March and June of 1985 a telephone interview was conducted by one of the authors with as many as possible of the 50 patients with new spinal cord injury who had participated in a previously reported study of urinary infection and complications occurring while using clean intermittent catherisation during initial hospitalisation (Maynard and Diokno, 1984). Patients reported what method of bladder management was currently being used and what was their medical history leading to any changes from one method to another. They also reported their degree of independence with the method, any problems or symptoms related to the method, their frequency of urological evaluation and the results, their estimated frequency per year of symptomatic urinary tract infections that were treated with antibiotics, all urological complications that had occurred and the number of hospitalisations for any urological problems. Medical records were reviewed whenever possible, to substantiate the diagnosis of any complications and results of urological evaluations.

\section{Results}

Only three of the 50 patients were unable to be interviewed; two had died of non-urological conditions and one patient could not be located. The seven patients with incomplete spinal cord injuries who were voiding normally at discharge had not experienced any further urological problems. The urological outcomes in the remaining 40 patients who all had a neuropathic bladder at discharge will be described in this report.

There were 33 men $\left(82^{\circ}{ }_{0}\right)$ and seven women $\left(18^{\circ}{ }_{0}\right)$. Eighteen $(45 \%)$ were quadriplegic and $22\left(55^{\circ}\right.$ o $)$ were paraplegic. At the time of interview they were an average of 60.1 months (range: $40-80$ months) post-injury. Twenty-three patients $\left(58^{\circ}{ }_{0}\right)$ had had a urological follow-up but only patient report of results was known.

Table I shows the method of urinary management at discharge as compared with the time of follow-up. Among 34 patients discharged using chronic clean intermittent catherisation (CCIC), $28\left(82^{\circ}{ }_{0}\right)$ continued to use it. Two patients electively changed to indwelling catheter drainage in order to improve independence. Three patients became catheter-free, with or without an external

Table I Method of Urinary Management at Time of Discharge and at the Time of Follow-up

\begin{tabular}{|c|c|c|c|c|c|c|c|}
\hline \multicolumn{2}{|c|}{ Management at discharge } & \multirow[t]{2}{*}{ CCIC } & \multirow[t]{2}{*}{$\begin{array}{l}\text { Indwelling } \\
\text { urethral } \\
\text { catheter }\end{array}$} & $\begin{array}{c}\text { SP } \\
\text { Catheter }\end{array}$ & \multirow[t]{2}{*}{ Conduit } & \multirow[t]{2}{*}{$\begin{array}{c}\text { Catheter } \\
\text { free }\end{array}$} & \multirow[t]{2}{*}{ Normal } \\
\hline & $\mathrm{N}$ & & & & & & \\
\hline $\begin{array}{l}\text { Chronic clean } \\
\text { intermittent } \\
\text { catheterisation }\end{array}$ & 34 & 28 & 1 & 1 & & 3 & 1 \\
\hline Indwelling urethral & 2 & & 1 & 1 & & & \\
\hline Suprapubic catheter & 2 & & & 1 & 1 & & \\
\hline Catheter free & 2 & & & & & 1 & 1 \\
\hline Follow-up totals & 40 & 28 & 2 & 3 & 1 & 4 & 2 \\
\hline
\end{tabular}


collector, one following a sphincterotomy. One patient regained normal voluntary voiding ability. There were no conduit procedures in this group and no changes in management due to upper urinary tract complications.

Among the four patients discharged using an indwelling urethral or suprapubic catheter, three continued to use them. One male patient using a suprapubic catheter was changed to ileal conduit drainage because of severe reflex sweating and autonomic hyper-reflexia associated with chronic bacteriuria and uncontrolled bladder spasms. Among the two patients discharged catheter-free, one continued reflex voiding with an external collector and the other regained normal control of voiding.

Urological complications occurring in the 34 patients discharged using CCIC included: minor urethral stricture 2, urethral false passage 1, epididymitis 3 $(9 \%)$, cystolithiasis $6\left(18^{\circ}{ }_{0}\right)$, nephrolithiasis 2 and hospitalisation for febrile or otherwise symptomatic urinary tract infection (SxUTI) $10(30 \%)$. Fifteen of the 34 patients $\left(44^{\circ}\right.$ o $)$ were hospitalised at least once during the 5 years for one or more of these urological complications.

In order to estimate the prevalence of SxUTI and its potential relationship to other complications, the 34 patients discharged using CCIC were grouped according to frequency of self-reported or documented ScUTI (Table II). Eleven patients in Group A had non or one (0-1) SxUTI since discharge and four of these 11 patients $\left(37^{\circ}\right.$ o $)$ were hospitalised for treatment of SxUTI and/or other urological complications. Nine patients in Group B had occasional (average of $<2$ year) SxUTI and two of these nine patients $(22 \%)$ were hospitalised for treatment of SxUTI and/or other urological complications. Fourteen patients in Group C had frequent (average of $>2$ year) SxUTI and/or other urological complications.

Most of the urological complications previously listed occurred in Group C

Table II Per cent of Patients Using CCIC Who were Hospitalised Once or More During 5 Year Follow-up for SxUTI and/or other Urological Complications in Groups with Different Frequencies of SxUTI. Group A had None or One SxUTI During Follow-up. Group B had Occasional SxUTI (average $<2$ /year). Group C had Frequent SxUTI (average > 2/year)

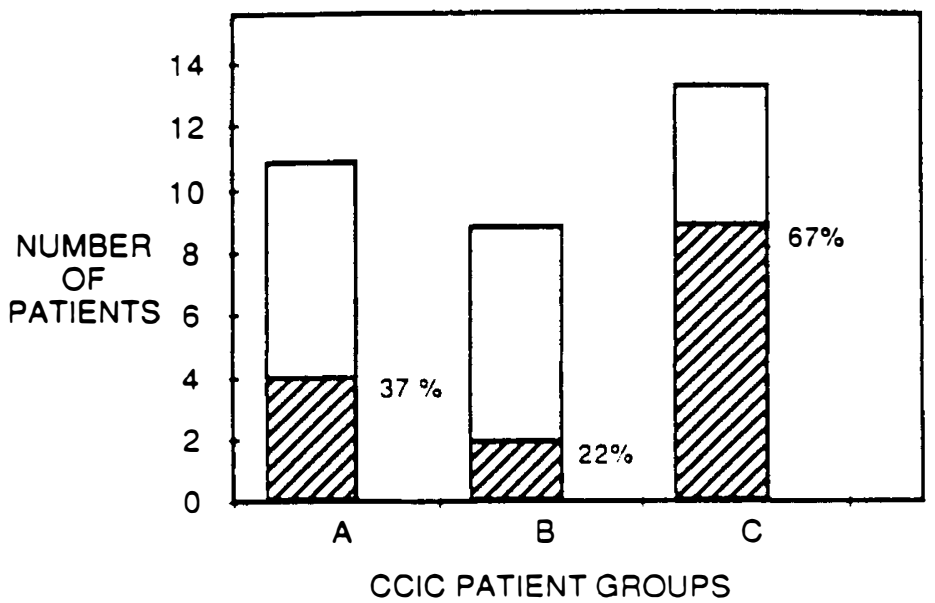


patients who had frequent SxUTI. The only urological complications in Groups $A$ and $B$ were three cases of crystolithiasis, one case of stricture and five cases of SxUTI treated in hospital. There were no urological complications among the six women who were discharged using and who continue to use CCIC, except one woman who had several hospitalisations for SxUTIs.

Among the four patients using indwelling catheters, urological complications included two patients hospitalised for SxUTI, including one with cystolithiasis. A third patient was hospitalised for the ileal conduit procedure described earlier. One patient had no hospitalisations for SxUTI or urological complications. There were no urological complications in the two patients discharged catheter-free.

Twenty-three of the 34 patients $(70 \%)$ using CCIC at discharge were totally independent in doing the procedure. Six $(18 \%)$ were only partially independent at discharge, usually requiring some assistance for clothes management and/or set-up of the equipment. Five $(12 \%)$ were totally dependent for self-catheterisation. At follow-up there were three patients who were totally independent and three patients who were dependent that had changed to other methods of management. Three of the patients who were partially independent at discharge had become totally independent at follow-up.

\section{Discussion}

In this study population 35 of the original 50 spinal cord injury patients $(70 \%)$ were using CCIC for urinary mangement at time of discharge and at time of follow-up 28 of 40 patients $(70 \%)$ were still using it. This $82 \%$ continued-use rate compares with an $86 \%$ continued-use rate found in a previous retrospective outcomes study (Maynard and Diokno, 1982). This figure itself suggests an acceptable frequency of medical morbidity and a high degree of social acceptance over 5 years.

The urological complications among patients in this study appeared to be largely confined to the lower urinary tract, although the frequency of asymptomatic upper tract changes or calculi may have been higher if results of a complete recent urological evaluation had been available on all patients. Only the one case of a urethral false passage had significant morbidity, requiring a surgical repair. The two known cases of nephrolithiasis were small in size and unassociated with pyelocaliectasis. A low frequency of upper tract problems has also been reported in other follow-up studies of patients using CCIC (McGuire and Savastano, 1983) (Maynard and Diokno, 1982).

Comparison of medical morbidity and urological outcomes among spinal cord injured patients using different methods of bladder management is made difficult by the many uncontrollable management variables within each method which may influence outcomes, by patient compliance with physician recommendations and by patient choice of physician provider. Additionally the influence of factors determining the choice of method cannot be separated from those influencing outcomes. A long-term study of 406 spinal cord injured in Ireland, $92^{\circ}$ o who were catheter-free, found a $9 \%$ incidence of cystolithiasis, $4 \%$ incidence of nephrolitiasis and a 10\% incidence of pyelocaliectasis (Webb et al., 1984). Pearman (1976) reported almost no complications among a series of 99 
spinal cord injured in Australia who were managed initially by sterile intermittent catheterisation and then in a catheter-free state. Interestingly he reported two patients with small renal calculi without pyelocaliectasis. In the U.S.A., Stover et al., (1977) reported a $30 \%$ incidence of pyelocaliectasis among 126 spinal cord injured, $74 \%$ who were catheter-free, at 2-6 year follow-ups.

This study did not obtain any exact or estimated costs of urological care and management. Frequency of hospitalisations does provide some estimate of costs since hospitalisations are so expensive. In this population $44 \%$ of all patients were hospitalised at least once in 5 years for urological problems. This figure can be compared to the results of a collaborative study by Young (1982). He reported $41^{\circ}$ o of complete injuries and $30^{\circ}$ o of incomplete injuries were hospitalised annually during the first 5 years after injury. The annual incidence of urinary complications in years following injury among hospitalised cases was $65^{\circ}{ }_{0}$. Thus the frequency of hospitalisations among patients using CCIC in this report is probably comparable to other groups of spinal cord injured using different urinary management methods in the U.S.A.

The low incidence of urinary complications among women patients using CCIC in this study is particularly interesting. Although the number of women is too small to allow statistical significance, it may be explained by the lower urethral outflow resistance of female anatomy which results in incontinence before damaging high intravesical pressures occur. Most of the women using CCIC required anticholinergic medication to control incontinence.

Although our experience demonstrates that some severely disabled quadriplegics can be managed well on CCIC in spite of their inability to be totally independent in the procedure, these results suggest that a lack of independence does influence the continued-use rate. Three of the five patients who were dependent for catheterisation changed to another method of management. This compares with only three of the 23 totally independent patients who later changed to another method of management, two changed because they believed self-management would be easier.

\section{References}

MCGuire E, Savastano JA 1983 Long-term follow-up of spinal cord injured patients managed by intermittent catherisation fournal of Urology 123:775-76.

MAYNARD FM, DIOKNO AC 1984 Urinary infection and complications during clean intermittent catheterisation following spinal cord injury fournal of Urology 132:943-46.

MAYNARD FM, DIOKNO AC 1982 Clean intermittent catheterisation for spinal cord injured patients fournal of Urology 128:477-80.

PEARMAN J 1976 Urological follow-up of 99 spinal cord injured patients initially managed by intermittent catheterisation fournal of Urology 48:297-310.

StOver SL, Lloyd LK, NePOMUCENo CS, et al. 1977 Intermittent catheterisation: Follow-up studies Paraplegia 15:38-46.

Stover SL et al. 1985 3rd Annual Report National Spinal Cord Injury Statistical Centre, University of Alabama, Birmingham, AL.

WEBB DR, FITZPATRICK JM, O'FLYNN JD 1984 A 15-Year follow-up of 406 consecutive spinal cord Injuries fournal of Urology 56:614-17.

Young JS, Burns PE, Bowen AM, et al. 1982 Spinal Cord Injury Statistics Good Samaritan Medical Centre, Phoenix AZ. 